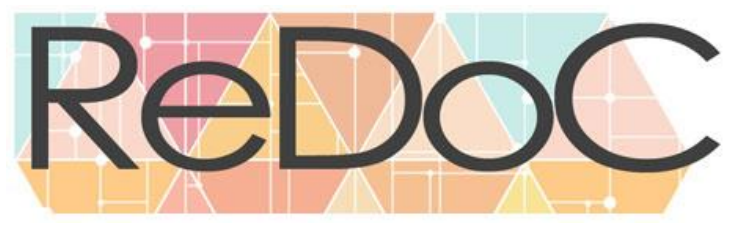

Revista Docência e Cibercultura

\title{
A PRÁTICA PEDAGÓGICA NO ESTÁGIO DO ENSINO FUNDAMENTAL
}

\section{THE PEDAGOGICAL PRACTICE IN THE STAGE OF FUNDAMENTAL TEACHING}

\section{LA PRÁCTICA PEDAGógICA EN EL PERÍODO DE PRÁCTICAS DE ENSEÑANZA PRIMARIA}

Fernando Silvio Cavalcante Pimentel ${ }^{1}$
Alane de Almeida Santos

RESUMO: Este trabalho apresenta as reflexões sobre a prática pedagógica do professor dos anos iniciais, juntamente com a experiência vivenciada pelos alunos da disciplina do Estágio Supervisionado IV em sua formação acadêmica. De natureza qualitativa, o estudo tem como instrumento tecnológico para coleta de dados, a pesquisa documental. $\mathrm{O}$ objetivo desse artigo é identificar as diferentes práticas metodológicas utilizadas pelos estagiários para mediar sua prática pedagógica na sala de aula, enquanto intervenção no Estágio do Ensino Fundamental I. Utilizamos como apoio teórico os estudos de Morais (1994), Saviani (2009), Tardif (2012), Libânio (1994), Documentos oficiais: LDB, PPC Pedagogia, entre outros. Nesse contexto, discute-se a Formação do professor, a Metodologia e a Didática do Ensino Fundamental; e por fim, apresentamos a análise dos dados, na qual expomos as metodologias mais utilizadas pelos alunos do Curso de Pedagogia em tempos de cibercultura.

PALAVRAS-CHAVE: Formação de professores. Práticas pedagógicas. Metodologias do ensino. Estágio Supervisionado. Ensino Fundamenta I.

Submetido em: 28/02/2018 - Aceito em: 03/04/2018 - Publicado em: 29/06/2018.

${ }^{1}$ Doutor em Educação (UFAL); Mestre em Educação pela Universidade Federal de Alagoas (2010), especialista em Tecnologias em Educação e Docência do Ensino Superior. Graduado em Pedagogia (Licenciatura). Foi professor - de escolas particulares, tutor do programa de formação continuada Secretaria de Educação a Distância - MEC, professor tutor 1 da Universidade Tiradentes e professor do Governo do Estado de Alagoas. Tem experiência na área de Educação, com ênfase em EnsinoAprendizagem, atuando principalmente nos seguintes temas: aprendizagem, educação online, webquest, tutoria, games (jogos online), gamificação e avaliação. Atualmente é professor adjunto da Universidade Federal de Alagoas. Foi Vice-coordenador da Coordenadoria Institucional de Educação a Distância e Coordenador Adjunto da UAB/UFAL.

${ }^{2}$ Pedagoga Universidade Federal de Alagoas (UFAL)

${ }^{3}$ Pedagoga Universidade Federal de Alagoas (UFAL) 


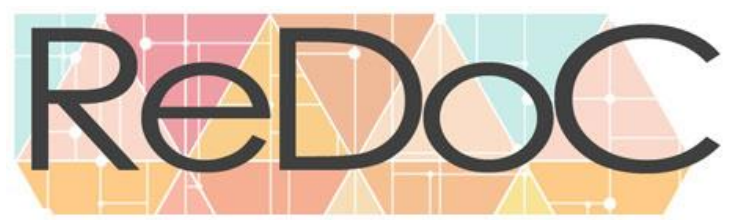

Revista Docência e Cibercultura

ABSTRACT: This work presents the reflections about the pedagogical practice of the teacher of the initial years associated with the experience of the students of the subject of Supervised Internship IV in his academic formation. Of qualitative nature, the study has as a technological instrument for data collection, documentary research. The objective of this article is to identify the different methodological practices used by trainees to mediate their pedagogical practice in the classroom, as an intervention in the Elementary School Stage I. We use as theoretical support the studies of Morais (1994), Saviani (2009), Tardif (2012), Libânio (1994), Official documents: LDB, PPC Pedagogy, among others. In this context, we discuss the teacher training, the Methodology and Didactics of Elementary Education and finally, we present the data analysis, in which we expose the methodologies most used by the students of the Pedagogy Course in cyberculture times.

KEYWORDS: Teacher training. Pedagogical practices. Teaching methodologies. Supervised internship. Elementary School.

RESUMÉN: Este trabajo presenta reflexiones sobre la práctica pedagógica del profesor de los años iniciales, juntamente con la experiencia vivida por los alumnos de la disciplina Prácticas Supervisadas IV en su formación académica. De naturaliza cualitativa, el estudio tiene como instrumento tecnológico para recoger datos, la investigación documental. El objetivo de este artículo es identificar las diferentes prácticas metodológicas utilizadas por los practicantes para mediar su práctica pedagógica en el aula, mientras se da su intervención en el período de prácticas en la enseñanza primaria. Utilizamos como apoyo teórico los estudios de Morais (1994), Saviani (2009), Tardif (2012), Libânio (1994), Documentos oficiales: LDB, PPC Pedagogía, entre otros. En este contexto, se discutió la formación del profesor, la metodología y la didáctica de la enseñanza primaria; y finalmente, presentamos el análisis de los datos, en donde exponemos las metodologías más utilizadas por los alumnos del curso de Pedagogía en tiempos de cibercultura.

PALABRAS CLAVE: Formación de profesores. Prácticas pedagógicas. Metodologías de la enseñanza. Etapa Supervisada. Enseñanza Fundamenta I.

\section{INTRODUÇÃO}

A prática pedagógica docente tem sido bastante discutida nos últimos tempos por se tratar de processos teóricos/metodológicos pelo qual o professor utiliza para promover a aprendizagem do aluno, direcionando caminhos da relação indissociável entre ensino e 


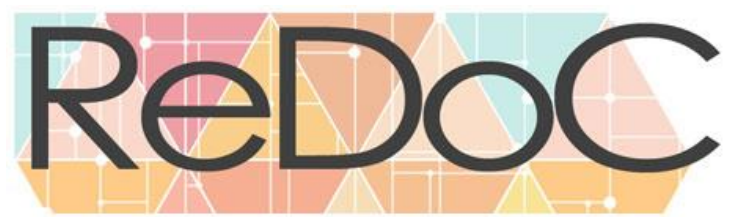

Revista Docência e Cibercultura

aprendizagem. Os estudos nesse campo educacional têm recebido um novo olhar a partir da cibercultura (LEMOS; CUNHA, 2003 e SANTOS, 2013).

A justificativa para essa pesquisa se situa a partir da curiosidade de compreender quais são os métodos de ensino que os estagiários escolheram no momento de elaborar as regências do estágio. Com a análise dos projetos elaborados por futuros professores, podemos observar se essas metodologias são propícias para alcançar o objetivo docente, que é articular a teoria e a prática para mediar o conhecimento por meio de uma prática pedagógica contextualizada.

Este artigo, originado da pesquisa empírica, estruturou-se em 4 tópicos: (1) apresenta-se abordagens teoricamente sobre a "Formação dos professores", (2) "Metodologia e Didática do Ensino Fundamental", (3) a "Metodologia da pesquisa" e (4) a "Análise dos dados coletados", tendo como objetivo estabelecer uma conexão entre os elementos anteriores. A investigação buscou reunir dados suficientes tendo como propósito responder ao seguinte problema de pesquisa: que metodologias são propostas e desenvolvidas nas práticas de intervenção do Estágio Supervisionado IV do Curso de Pedagogia?

Dentro da temática, o presente artigo tem como objetivo identificar as metodologias utilizadas pelos alunos do Curso de Pedagogia da Universidade Federal de Alagoas (UFAL), na tentativa de analisar as diferentes práticas pedagógicas que foram mediadas durante seu exercício na sala de aula, enquanto intervenção no Estágio do Ensino Fundamental I.

Configurada como uma pesquisa documental, utilizou como instrumento tecnológico para coleta de dados os projetos de intervenção. Além disso, optou-se por uma abordagem de natureza qualitativa, tendo como fundamento teórico Silveira e Córdova, 2009.

Para o embasamento teórico para a presente discussão nos utilizamos das ideias de Morais (1994), ao tratar dos conceitos das mudanças ocorridas nas formações dos professores, a relação entre a teoria e a prática, a criação de Centros Específicos de Formação e Aperfeiçoamento do Magistério (CEFAMs); Saviani (2009), ao investigar 


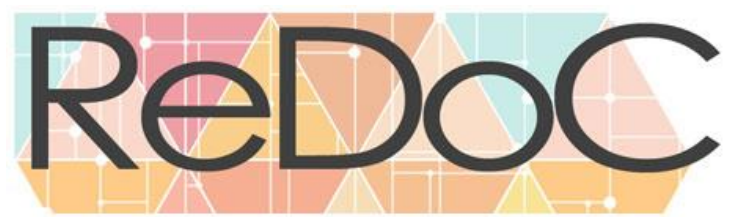

\section{Revista Docência e Cibercultura}

sobre os objetivos de se tornar um educador; Tardif (2012) que evidencia a base teórica, os conhecimentos profissionais, a formação profissional; Libânio (1994), que conceitua a metodologia do ensino e a didática; e além da Lei 9.394 de 1996, e o PPC do Curso de Pedagogia.

\section{FORMAÇÃO DOS PROFESSORES: NUM CONTEXTO DE HISTÓRIA}

O campo de estudo sobre a formação de professores é delineado pelo entendimento de que as mudanças sociais foram provocando a necessidade de repensar quem poderia estar em sala de aula no ofício de educar.

Historicamente, a imagem do professor era a voz dos novos dispositivos de escolarização, com isso criou-se condições a sua profissionalização, como afirma Nóvoa (1954, p. 2-3):

Ao longo do século XIX consolida-se uma imagem do professor, que cruza as referências ao magistério docente, ao apostolado e ao sacerdócio, com a humildade e a obediência devidas aos funcionários públicos, tudo isto envolto numa auréola algo mística de valorização das qualidades de relação e de compreensão da pessoa humana. [...] $\mathrm{Na} 1^{\text {a }}$ metade do século XIX implementaram-se mecanismos progressivamente mais rigorosos de selecção e de recrutamento do professorado. Mas, quando foi preciso lançar as bases do sistema educativo actual, a formação de professores passou a ocupar um lugar de primeiro plano: desde meados do século XIX que o ensino normal constitui um dos lugares privilegiados de configuração da profissão docente.

Contudo, entende-se que para formar um professor, vem sendo exigidos mecanismos mais rigorosos de seleção, percebendo-se que o trabalho docente compõe artifícios, práticas, reflexão e dedicação perante a profissão. Exige-se mais do que ensinar: o professor pode promover situações de interação, reflexão, debates, diálogo, ajudando o aluno a ter um olhar crítico para a sociedade do qual faz parte. Nesse contexto, formar um professor exige flexibilidade para escutar, bem como, preocupar-se em ensinar os alunos a tomar iniciativas para lidar com as dificuldades, deixando de serem apenas modelos a serem seguidos. 


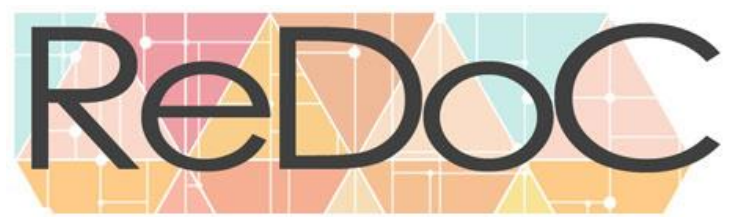

Revista Docência e Cibercultura

As autoras Vicentini e Lugli (2009) explanam que antes das instituições se estruturarem, o ensino era algo individualizado, onde a formação dos futuros mestres passava por um acompanhamento de um profissional durante todo o processo de formação. Esse profissional se encarregava de ensinar a lecionar, ou seja, antes para que o sujeito pudesse ensinar, este necessitaria somente ter um atestado de moralidade e o saber do que iria ensinar, em outras palavras, não havia um modelo de currículo para ser adotado.

No século XIX, surge a discussão sobre a forma adequada de qualificar o professor associado à necessidade de treinar soldados a fim de torna-los disciplinados, bem como, a educar a população que vivia na ignorância. Nesse contexto, o treinamento efetuado com os militares, servia de norte para a educação daqueles que não podiam frequentar as aulas estatais de primeiras letras. (VICENTINI; LUGLI, 2009)

Para Morais (1994), a formação dos professores no Brasil é um momento histórico, pois a importância da articulação entre a teoria e a prática nesse desenvolvimento é essencial no campo social. Com a compreensão de que a formação dos professores é algo que deve sempre ser repensado e estruturado, mudanças significativas foram promovidas na formação de professores e, consequentemente, na concepção de estágio no Brasil.

Entre essas mudanças, destaca-se a Constituição Federal de 1988, a Lei de Diretrizes e Bases da Educação Nacional nº 9.394/96 (BRASIL, 1996), e a extinção dos de Centros Específicos de Formação e Aperfeiçoamento do Magistério (CEFAMs) em 2003, tendo em vista que o artigo 62 da LDB 9.394/96 determina que a formação para professores deva ocorrer obrigatoriamente em nível superior. Em decorrência disso, as instituições do ensino superior têm como responsabilidade proporcionar formação de professores para atuar neste nível de ensino, bem como, universalizar a prática docente a partir das orientações das leis educacionais em vigor.

Conforme o Ministério da Educação (MEC, 2016, p. 01), “[...] A reforma universitária, em 1968, foi a grande LDB da educação superior, ao assegurar autonomia didático-científica, disciplinar, administrativa e financeira às universidades”. A reforma 


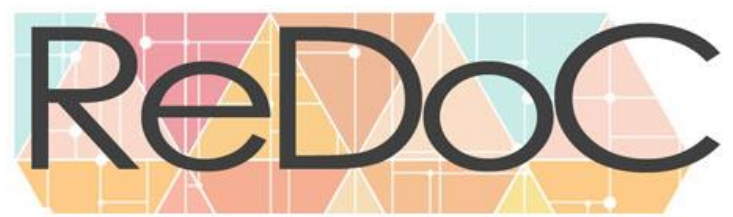

\section{Revista Docência e Cibercultura}

representou um avanço na educação superior brasileira, ao instituir um modelo organizacional único para as universidades públicas e privadas.

A partir dessa reforma, as mudanças efetivamente favoreceram tanto ao professor, quanto o aluno, pois verifica-se que, com a qualificação necessária, os educadores desenvolvem suas competências e habilidades com mais segurança e profissionalismo em seu cotidiano acadêmico.

Ainda antes das legislações que atualmente definem o perfil formador de professores, no contexto da Universidade Federal de Alagoas (Ufal), amparada e provocada pela lei da educação superior à época, o curso de Pedagogia

[...] nasce precipuamente para formar técnicos em nível de especialização na área de educação, capazes, sobretudo, de assessorar os sistemas educacionais àquela altura em processo de modernização, como, aliás, definia a legislação em vigor. Já no âmbito da UFAL e ligada à unidade então chamada de FACULDADE DE FILOSOFIA, CIENCIAS E LETRAS DE ALAGOAS, a área de educação, além de formar graduados e graduadas em PEDAGOGIA, continuou a desenvolver ações acadêmicas inerentes à formação de todos/as os/as graduados/as pela Universidade aptos/as a, legal e plenamente, exercer a função de professores/as nos chamados cursos secundários, enquanto formava, emergencialmente, também aqueles/as que, na prática, se tinham feito professores e professoras (VERÇOSA et al., 2006, p. 15 , negrito do autor).

Desde sua origem o curso de Pedagogia da Ufal tem como pretensão formar um profissional que contribua com o desenvolvimento e aprendizagem do aluno.

Após a criação do curso no Estado, uma nova reforma universitária foi promovida pelo regime militar. Conforme Verçosa et al. (2006, p. 15-16) com a

reforma universitária promovida pelo Regime Militar, através da lei 5.540/68, na UFAL, em fins da década de 1960, foi promovida uma reorganização institucional, da qual saiu a estrutura de INSTITUTOS BÁSICOS e FACULDADES, vindo a área de educação a constituir a FACULDADE DE EDUCAÇÃO, com a responsabilidade de formar ou concluir a formação de todos os profissionais da educação em nível superior, em Alagoas, através de clássico esquema $3+1$ criado, no Brasil, com a estrutura original das licenciaturas, ainda na década de 30 (negrito do autor).

Com essa nova reforma, o curso foi estruturado conforme o esquema citado acima, garantido pelo parecer CNE/CP 2005. O curso de Pedagogia oferecia o título de bacharel, 


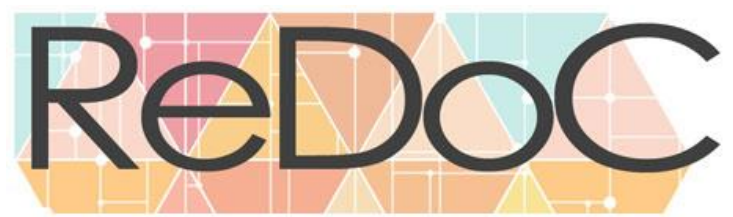

\section{Revista Docência e Cibercultura}

a quem cursasse três anos de estudos em conteúdos específicos da área, que eram os fundamentos e teorias educacionais; e o título de licenciado que permitia atuar como professor, aos que, tendo concluído o bacharelado, cursasse mais um ano de estudos, dedicado à Didática e à Prática de Ensino.

Entretanto, tendo como base a LDB 9.394/1996, o profissional da educação conclui o curso em nível superior, com perfil de um profissional capaz de exercer a docência, a pesquisa e a gestão dos processos educativos, como assegura Verçosa (2006, p. 32):

O Curso de Licenciatura em Pedagogia do Centro de Educação da UFAL destina-se à formação de licenciados/as para exercer funções de magistério na Educação Infantil e nos anos iniciais do Ensino Fundamental, nas disciplinas pedagógicas dos cursos de Ensino Médio, na modalidade Normal, na Educação Profissional na área de serviços e apoio escolar, bem como para exercer atividades de organização e gestão de sistemas e instituições de ensino, englobando planejamento, execução, coordenação, acompanhamento e avaliação de tarefas próprias do setor da Educação e produção e difusão do conhecimento científico-tecnológico do campo educacional, em contextos educacionais.

Sendo assim, os componentes curriculares comuns para os cursos de formação de professores da Ufal esclarecem que o profissional é licenciado para trabalhar não só numa instituição educacional, mas, em áreas destinadas a sua formação, associando a teoria e a prática no seu ambiente de trabalho.

Em relação à teoria e a prática docente, Morais (1994) afirma que no Brasil na década de 1980 foi implementado Centros Específicos de Formação e Aperfeiçoamento do Magistério (CEFAMs). Esses centros apresentaram como objetivo tentar romper com a dissociação entre teoria e prática na formação de professores.

A criação do CEFAMs, provocou a necessidade de repensar outro projeto já existente: o curso Habilitação Específica para o Magistério (HEM), em nível de $2^{\circ}$ grau e que formava professores para o exercício do magistério de $1^{\circ}$ grau à época.

$\mathrm{Na}$ atualidade, os cursos ofertados para os professores se configuram num quadro de insegurança, no que diz respeito aos problemas relacionados à teoria e à prática. Ainda há um grande distanciamento entre o que se ensina nos cursos de formação de professores 


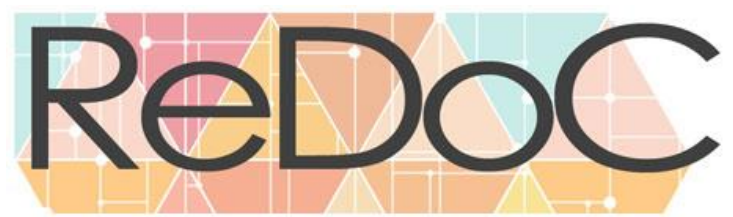

\section{Revista Docência e Cibercultura}

e o contexto educacional atual, inclusive quando pensamos numa sociedade em que as crianças, inseridas na cibercultura, apresentam particularidades signicativas que devem ser compreendidas, pois refletem diretamente na forma como devem ser educadas.

Assim sendo, Pimenta (2005; 2006) complementa que essas situações de distanciamento entre teoria e prática ocasionam prejuízos pedagógicos na vida dos futuros professores, não somente nesses cursos, mais também nos cursos especiais de formação de professores realizados em convênios entre secretarias de educação e universidades.

Na direção de aprofundar as discussões sobre essa problemática, em relação a formação de professores e os saberes docentes, surgem com marca da produção intelectual internacional o desenvolvimento de estudos que utilizam uma abordagem teórica metodológica que dá a voz ao professor, a partir da análise de trajetórias e histórias de vida (NUNES, 2001).

Essa formação contextualizada exige do professor uma visão crítica sobre suas representações pessoais, seu ponto de vista e suas crenças sobre a educação, bem como sobre o ambiente escolar e as problemáticas que surgirão.

Para Nóvoa (apud NUNES, 1995), essa visão crítica veio em oposição aos estudos anteriores que acabavam por reduzir a profissão docente a um conjunto de competências e técnicas, gerando uma crise de identidade dos professores em decorrência de uma separação entre o eu profissional e o eu pessoal.

Essas novas propostas formativas passaram a ter o professor como foco central em estudos e debates, considerando o quanto o modo de vida pessoal acaba por interferir no profissional. Nunes (2001, p. 29) acrescenta que esse movimento surgiu "num universo pedagógico, num amálgama de vontades de produzir outro tipo de conhecimento, mais próximo das realidades educativas e do quotidiano dos professores".

Partindo do pressuposto de que o conhecimento profissional do professor é um conjunto de saberes consistentes de relação entre teorias e experiências, é preciso compreender que esses saberes servirão como análise da realidade e compreensão para o aperfeiçoamento didático, com a interferência pessoal, e com o desenvolvimento de um trabalho pedagógico a partir da situação do próprio cotidiano profissional. 


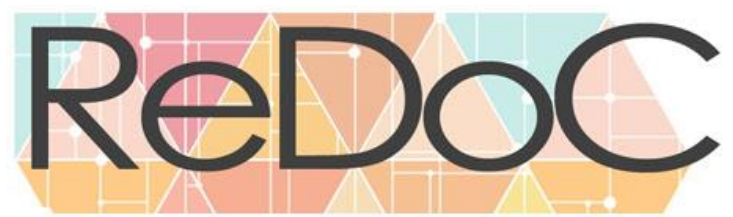

\section{Revista Docência e Cibercultura}

Tratando-se dos objetivos de uma determinada ação, Saviani (2009) revela que o educador necessita antecipar mentalmente suas ideias. Nesta perspectiva, essa produção de ideias será o conhecimento, seja ele sobre a natureza, ou sobre a cultura que abarca o conjunto da produção humana. Neste sentido, o autor salienta que a educação se enquadrará na categoria do trabalho não material.

A constituição da profissão docente no Brasil, parte do reconhecimento de que a profissionalização cresce na educação na proporção em que são ampliados os sistemas escolares, os padrões de organização educacional e escolar decorrentes dessas mudanças, podem estar constituindo um novo perfil de trabalhador docente.

Com isso, Ostetto (2008, p. 128) afirma:

a formação do professor envolve muito mais que uma racionalidade teóricotécnica, marcada por aprendizagens conceituais e procedimentos metodológicos. Há, no reino da prática pedagógica e da formação de professores, muito mais que domínio teórico, competência técnica e compromisso político. Lá estão histórias de vida, crenças, valores, afetividade, enfim, a subjetividade dos sujeitos implicados.

Dessa forma, a formação profissional requer uma prática expressiva que assuma perante a sociedade, um empoderamento para o docente desenvolver suas técnicas, habilidades, teorias e práticas, possibilitando condições e saberes necessários para sua atuação. Tardif (2012, p. 249) complemente que,

tanto em suas bases teóricas quanto em suas consequências praticas, os conhecimentos profissionais são evolutivos e progressivos e necessitam, por conseguinte, de uma formação contínua e continuada. Os profissionais devem, assim, autoformar-se e reciclar-se através de diferentes meios, após seus estudos universitários iniciais. Desse ponto de vista, a formação profissional ocupa, em principio, uma boa parte da carreira e os conhecimentos profissionais partilham com os conhecimentos científicos e técnicos a propriedade de serem revisáveis, criticáveis e passíveis de aperfeiçoamento.

O autor considera que a base teórica passa por processos de transformações que auxilia o profissional em seu desenvolvimento, salientando que essas transformações são evolutivas e segue uma linha de continuidade conforme a suas experiências docentes.

No entanto, Carrer (1996, p. 247) garante que: 


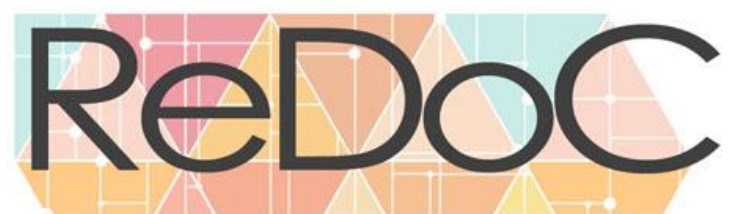

\section{Revista Docência e Cibercultura}

[...] é impossível desconsiderar que a atuação docente é, ao mesmo tempo, causa e efeito dessa realidade escolar. Por si só, a atuação docente não é capaz de produzir mudanças significativas nos sistemas educacionais, mas com certeza é um dos componentes importantes para que essa mudança ocorra.

Para esse autor o trabalho docente é uma atividade relevante, que exige do profissional dedicação e competência para produzir as mudanças que dão sentido a todo o sistema educacional, para que a atuação do docente tenha significado positivo no processo de aprendizagem.

\section{METODOLOGIA E DIDÁTICA DO ENSINO FUNDAMENTAL}

O entendimento de que o profissional docente é um dos responsáveis pelo desenvolvimento de uma educação de qualidade, faz pensar sobre a metodologia e a didática que deve utilizar no cotidiano de sua atividade laboral.

Especificamente quando se trata do Ensino Fundamental, percebe-se ser significativo compreender a dinâmica da interação entre o conhecimento elaborado e desenvolvido no decorrer dos séculos com a realidade cultural que é vivenciada em sociedade. Essa etapa da Educação Básica precisa ser pensada a partir de várias particularidades, tais como o tempo e o modo de oferta.

A implantação de uma política de ampliação do Ensino Fundamental de oito para nove anos de duração exige tratamento político, administrativo e pedagógico, uma vez que o objetivo de um maior número de anos no ensino obrigatório é assegurar a todas as crianças um tempo mais longo de convívio escolar com maiores oportunidades de aprendizagem. (BEAUCHAMP; PAGEL; NASCIMENTO, 2007). Portanto, a criança fará jus a essa oportunidade de manter-se por mais tempo na instituição e assim usufruir de tudo que a escola disponibiliza para seu desenvolvimento.

Sancionada a Lei $\mathrm{n}^{\circ} 10.172$, de 9 de janeiro de 2001, que estabelece o Plano Nacional de Educação, foi ampliado para nove anos a duração do Ensino Fundamental obrigatório com início aos seis anos de idade, e tem como objetivo oferecer maiores 


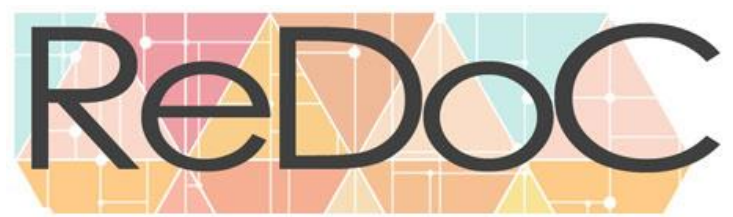

\section{Revista Docência e Cibercultura}

oportunidades de aprendizagem no período da escolarização obrigatória e assegurar que, ingressando mais cedo no sistema de ensino, as crianças prossigam nos estudos alcançando maior nível de escolaridade.

Sendo assim, a lei citada acima ajuda a esclarecer quanto mais cedo às crianças ingressarem na escola, melhor será sua adaptação na sala de aula e em todos os espaços que a escola oferece, com relação a sua aprendizagem e desenvolvimento, físico, psicológico, intelectual e social.

A aprendizagem do aluno depende muito do professor com sua concepção em relação a ele. Os professores são responsáveis pelo desenvolvimento do aluno através da prática educativa. Libânio (1994, p. 55) afirma que "[...] o ensino, por mais simples que possa parecer à primeira vista, é uma atividade complexa: envolve tanto condições externas como condições internas das situações didáticas".

Na busca de compreender conceitualmente, Libânio (1994) afirma que a metodologia do ensino consiste em métodos que o professor utiliza como meio para facilitar o conteúdo para os educandos. Com isso, o educador segue uma linha de conhecimento para alcançar seus objetivos diante do processo de ensino-aprendizagem. $\mathrm{O}$ autor ainda afirma que a metodologia pode ser geral ou específica, no que se refere aos procedimentos de ensino e estudos das disciplinas do currículo, ou ao que se refere a setores da educação escolar ou extra-escolar.

Para Libânio (1994), a didática tem muitos pontos em comum com as metodologias especificas de ensino. Elas são as fontes da investigação didática, ao lado da Psicologia da Educação e da Sociologia da Educação. Mas, ao se constituir como teoria da instrução e do ensino, abstrai das particularidades de cada matéria para generalizar princípios e diretrizes para qualquer uma delas.

Costa et al (2003, p. 35) afirmam que:

observando a prática dos profissionais da educação percebemos características diferenciadas em sua atuação pedagógica. Tais diferenças advêm de concepções filosóficas, conhecimentos científicos e opções politicas presentes no imaginário dos professores, que se refletem em suas visões, de homem e de educação. Essas concepções 


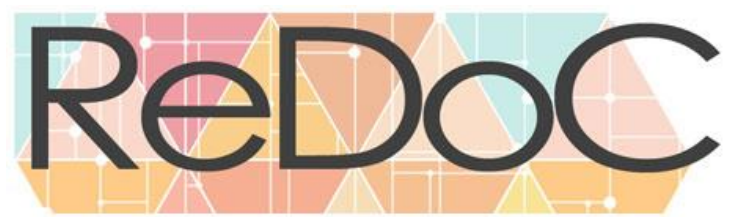

\section{Revista Docência e Cibercultura}

têm em base assentada em teorias filosóficas e cientificas e em intencionalidades sócio-políticas.

Assim sendo, os métodos de ensino são indispensáveis no cotidiano do professor em ação, já que ele é um sujeito ativo que constrói o conhecimento, e não um ser passivo que apenas responde a estímulos externos. Com isso, as práticas pedagógicas constituemse em um campo de conhecimento da educação que ajuda na formação dos professores em sua tarefa do dia-a-dia, criando um conjunto de condições para uma vida melhor na sociedade em que vivemos.

A prática não é apenas uma exigência da vida em sociedade, mas o processo de promover o indivíduo ao conhecimento e experiências culturais que tornam aptos a atuar no meio social e a transforma-lo, em função de necessidade econômica, social, política e da coletividade. Os professores precisam levar em consideração que muitos alunos trazem informações que atribuem na socialização da aula, e por isso observa-se necessário ampliar e aproveitar a democratização da informação.

\section{METODOLOGIA DA PESQUISA}

A presente pesquisa, desenvolvida a partir de uma abordagem de natureza qualitativa, considerada assim por não se preocupar com representatividade numérica, mas com o aprofundamento da compreensão de um grupo social, de uma organização, etc. [...]. Os pesquisadores que utilizam os métodos qualitativos buscam explicar o porquê das coisas, exprimindo o que convém ser feito, mas não quantificam os valores e as trocas simbólicas nem se submetem à prova de fatos, pois os dados analisados são não-métricos (sucintos e de interação) e se valem de diferentes abordagens (SILVEIRA; CÓRDOVA, 2009).

Tendo como instrumento tecnológico para coleta de dados, a pesquisa documental, trilha os mesmos caminhos da pesquisa bibliográfica, não sendo fácil por vezes distingui-las. A pesquisa bibliográfica utiliza fontes constituídas por material já elaborado, constituído basicamente por livros e artigos científicos localizados em 


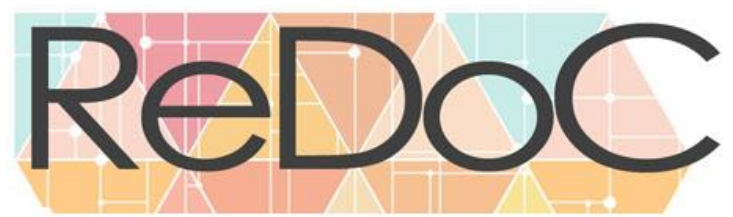

Revista Docência e Cibercultura

bibliotecas. A pesquisa documental recorre a fontes mais diversificadas e dispersas, sem tratamento analítico, tais como: tabelas estatísticas, jornais, revistas, relatórios, documentos oficiais, cartas, filmes, fotografias, pinturas, tapeçarias, relatórios de empresas, vídeos de programas de televisão, etc. (SILVEIRA; CÓRDOVA apud FONSECA, 2002, p. 32). Nesse sentido, os dados coletados nessa investigação foram os projetos de intervenção elaborados por estagiários do Curso de Pedagogia, especificamente junto à disciplina Estágio Supervisionado IV (Estágio no Ensino Fundamental)

Os dados coletados e analisados foram consultados no acervo da disciplina Estágio Supervisionado IV, a partir da busca por relatórios finais do Estágio supervisionado do Ensino Fundamental I, dos estagiários do curso de Pedagogia da Ufal. Nesses relatórios se encontram os projetos de intervenção, como também o relato das práticas de estágio.

Os projetos selecionados foram rigorosamente analisados, segundo a ótica proposta por esta pesquisa, observando e catalogando o que estava disposto no tópico "Procedimentos Metodológicos", tendo em vista que esse item faz parte do projeto de intervenção. O foco do olhar criterioso sobre esse item objetivou observar e listar as preferências dos métodos indicados pelos estagiários para desenvolver a regência de seus projetos.

A análise foi subdividida em cinco estratégias, compreendidas como categorias de análise: 1 - Os projetos que focam em atividades expositivas; 2 - Projetos que trabalham com jogos; 3 - Projetos que trabalham com literatura infantil; 4 - Projetos que evidenciam a participação ativa do aluno; e por fim, 5 - Os tipos de materiais que são utilizados para o desenvolvimento das aulas.

\section{ANÁLISE DOS DADOS}




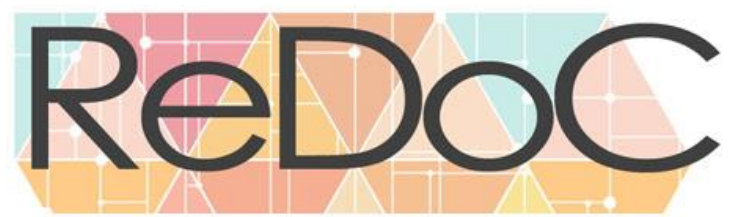

\section{Revista Docência e Cibercultura}

Ao tratar de coleta de dados, o passo seguinte consiste em realizar um procedimento de manipulação para chegar conferir nos dados as categorias elencadas, e assim poder realizar sua análise e interpretação (GIBBS, 2009). A análise que decorre dessa categorização, no contexto dessa investigação, procurou compreender sobre as práticas pedagógicas no estágio do Ensino Fundamental I, tendo como percepção 11 projetos finais de estágio do curso de Pedagogia/Licenciatura da Ufal.

\section{EIXOS ANALISADOS}

A coleta de dados foi realizada no ano de 2016, por meio de projetos finais dos estagiários da disciplina Estágio Supervisionado IV, do Curso de Pedagogia da Ufal. Os resultados mostram as principais metodologias de ensino apresentados nos projetos, oferecendo subsídios para análise dos referentes a métodos apropriados.

Os resultados dispostos no Gráfico 1 apresentam o quantitativo dos métodos identificados nos projetos analisados. Observa-se que a maior concentração de projetos que utilizaram a prática metodológica estão nas (a) atividades expositivas e na (b) participação ativa dos alunos; a concentração que utilizaram (c) jogos e (d) literatura infantil como possibilidades metodológicas é menor.

Percentualmente, detecta-se que nos projetos analisados, que 32\% indicaram realizar atividades expositivas, $31 \%$ indicou que utilizou como procedimento a participação ativa dos alunos nas aulas. $20 \%$ dos projetos indicam a utilização de jogos e $17 \%$ empregaram literatura infantil nas aulas.

Gráfico 1: Métodos apresentados nos projetos 


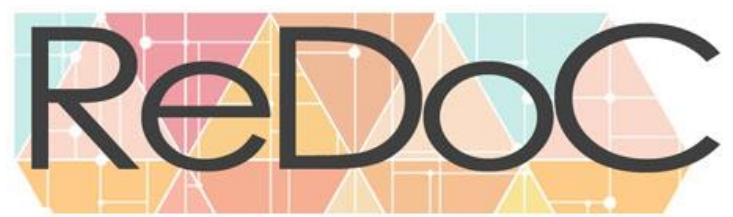

Revista Docência e Cibercultura

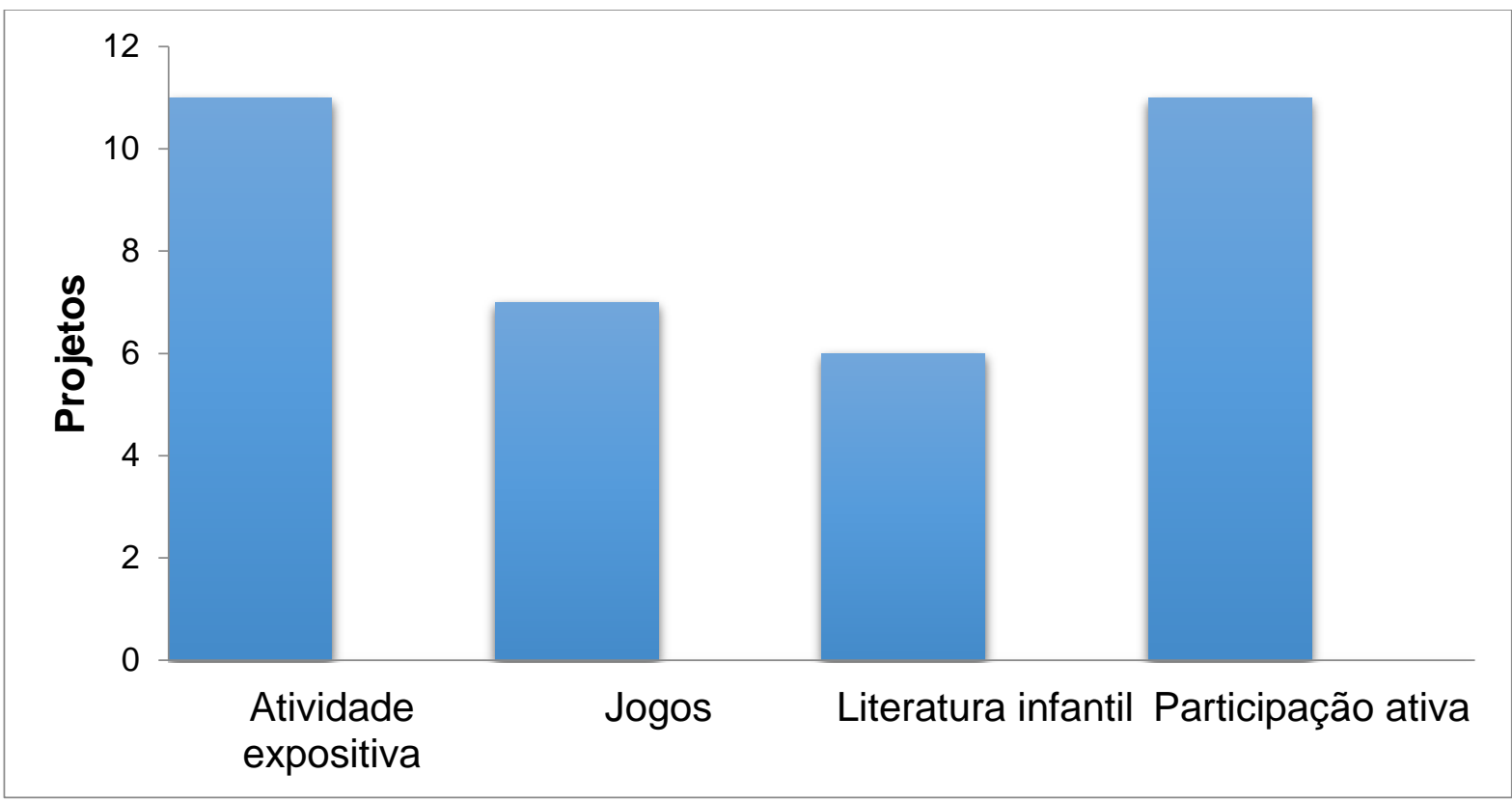

Fonte: Acervo da disciplina Estágio IV, a partir da busca por relatórios finais dos estágios supervisionados do Ensino Fundamental I (2016)

No primeiro eixo, buscamos identificar quantos projetos focaram as atividades em propostas expositivas. Segundo os relatórios analisados, todos os projetos apresentados realizaram uma didática ativa e expositiva. Essas atividades identificadas como didática ativa e expositiva foram: exposição de letras e figuras no quadro branco e em caixas, exposição de cartazes, exposição de histórias ilustrativas (HQ), utilização de vídeos, DVD, data show, músicas, confecção de materiais, poemas, painéis e brinquedos, exposição de fotos, jornais e acervos. Conforme Libânio (1994) esses tipo de atividade enfatiza que o professor centralize seus conteúdos de uma forma ativa, valorizando o processo de aprendizagem do aluno.

Observa-se também que já existem indícios da utilização das Tecnologias da Informação e Comunicação (TICs), sendo um elemento indispensável na conjuntura da Cultura Digital.

$\mathrm{Na}$ análise do segundo eixo, buscamos identificar quantos projetos focaram as atividades utilizando jogos. Dos onze projetos analisados, somente sete realizaram atividades com jogos. Para Carneiro (apud GUIMARÃES, 2014, p. 14), “aualquer tipo 


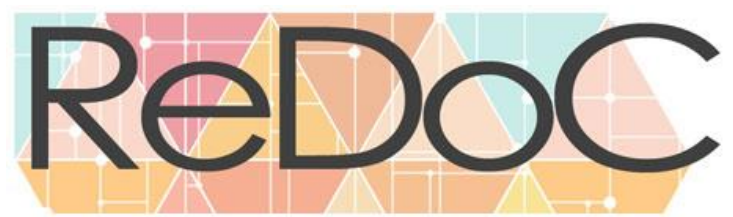

Revista Docência e Cibercultura

de jogo que seja desenvolvido na escola é importante, porém o que mais interessa é o ‘jogo didático', isto é, aquele usado com a finalidade de trabalhar determinado conteúdo". Desde então, o jogo é uma das ferramentas utilizadas pelos estagiários, tendo como objetivo tornar a aula mais dinâmica, sem perder o foco de alcançar seu objetivo final: a aprendizagem.

Das diversas formas de tornar a aula dinâmica, os projetos propuseram jogos, tais como: dinâmica de grupo, jogo do boliche, labirinto matemático, jogo da trilha matemática, jogo da amarelinha, jogos pedagógicos, jogo da memória, jogo de tabuleiro, brincadeira "Escravo de jó", pé de lata, bambolê, bola, corda. Observa-se que ainda há uma limitação para o uso de jogos digitais.

Já no terceiro eixo, buscamos identificar quantos projetos trabalharam com Literatura Infantil. Conforme a análise, somente seis projetos realizaram atividades com esse instrumento. Foram desenvolvidas, conforme os projetos: cantigas de roda, poesia, poema, parlenda e músicas infantis consideradas literaturas. Segundo Paço (2009), a Literatura Infantil torna-se uma descoberta de mundo para as crianças, fazendo com que elas busquem o interesse pela leitura, despertando assim o habito e o prazer de ler.

Nos projetos analisados, que seu utilizaram da literatura infantil como recurso didático, percebe-se que esse recurso foi trabalhado de diversas formas. Durante as regências, as músicas foram utilizadas no formato de cantoria coletiva, exploração das letras e palavras das músicas, como também o desenvolvimento de coreografias; nas cantigas de rodas foram trabalhadas coletivamente as letras das músicas para consequentemente realizarem atividades de formação de palavras e confecção de cartazes.

Foram identificadas também poesias, das quais destacamos "A casa” de Vinicius de Morais, sendo realizado um momento de exploração da escrita, como também do contexto musical da poesia. Nos projetos também identificamos poemas que foram lidos com os alunos a partir de leitura coletiva, reflexão e atividade dirigida, a exemplo do poema de Manoel Bandeira "O Bicho" e da leitura coletiva e atividade proposta do poema "Meio Ambiente"; houve debate sobre os poemas de figuras ilustres africanas, a partir da 


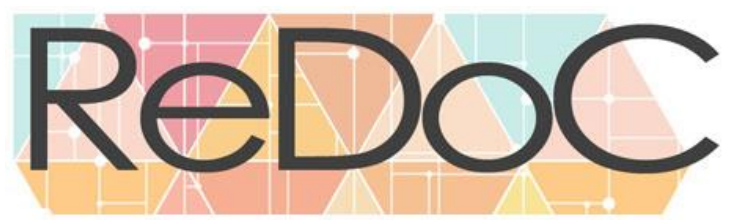

Revista Docência e Cibercultura

leitura e exploração das figuras, foram distribuídas para os alunos. Visualizamos também atividades realizadas com parlenda, sendo realizada a leitura e uma atividade escrita registrando palavras desse recurso.

No quarto eixo, procuramos identificar se em todos os projetos ficou evidente a participação ativa dos alunos. Ao analisar, ficou constatado que todos os projetos comprovaram que os alunos foram ativos nas atividades propostas e realizadas durante a regência. Sendo assim, Freire (2011, p. 83-84) “[...] o bom professor é o que consegue, enquanto fala, trazer o aluno até a intimidade do movimento de seu pensamento". Conforme o autor é um meio que o docente busca para ajudar o aluno a tornar mais participativo em sala de aula.

Quadro 1: Materiais utilizados nos projetos ${ }^{4}$

\begin{tabular}{|l|l|l|l|}
\hline ESCOLARES & ELETRÔNICOS & RECICLÁVEIS & OUTROS \\
\hline
\end{tabular}

${ }^{4} \mathrm{O}$ Quadro 1 apresenta os principais materiais utilizados durante as regências. 


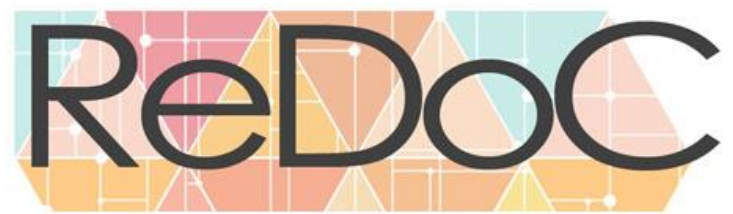

Revista Docência e Cibercultura

\begin{tabular}{|c|c|c|c|}
\hline $\begin{array}{l}\text { - } \text { Papel A4 } \\
\text { - } \text { Papel } 40 \mathrm{~kg} \\
\text { - } \text { Fitas adesivas } \\
\text { - } \text { Tesouras } \\
\text { - } \text { Colas } \\
\text { - Canetas } \\
\text { coloridas } \\
\text { - Pinceis para } \\
\text { quadro branco } \\
\text { - } \text { Cartolina guache } \\
\text { - } \text { Livros de } \\
\text { histórias em } \\
\text { quadrinhos } \\
\text { - Lápis } \\
\text { - } \text { Borracha } \\
\text { - Réguas } \\
\text { - Dados } \\
\text { - Mapas } \\
\text { - Livros didáticos } \\
\text { - Pistola de cola } \\
\text { - } \text { Tuente } \\
\text { - } \text { Linta guache } \\
\text { - } \text { paradidático } \\
\text { - Papel sulfite }\end{array}$ & $\begin{array}{ll}\text { - } & \text { Datashow } \\
\text { - } & \text { Delevisão } \\
\text { - } & \text { Aparelho de som } \\
\text { - } & \text { Pen drive }\end{array}$ & $\begin{array}{l}\text { - } \text { Jornais } \\
\text { - } \text { Revistas } \\
\text { - } \text { Canudos pets } \\
\text { - } \quad \text { Caixa de papelão } \\
\text { Sucata }\end{array}$ & $\begin{array}{l}\text { - } \text { Quadro branco } \\
\text { - } \text { Agulinas } \\
\text { - } \text { Bolas } \\
\text { - } \text { Peões } \\
\text { - Chapeis } \\
\text { Espelho } \\
\text { - Cadeiras } \\
\text { Barbante } \\
\text { Alimentos } \\
\text { (amendoim, } \\
\text { mungunzá, } \\
\text { tapioca, etc.) } \\
\text { Elástico } \\
\text { Tecidos } \\
\text { atoalhados } \\
\text { Detergente } \\
\text { Bambolê } \\
\text { Corda }\end{array}$ \\
\hline
\end{tabular}

Fonte: Dados da pesquisa (2017)

Foi possível visualizar essa participação ativa dos alunos por meio da leitura dos tópicos sobre a avaliação das aulas regidas, outro item que consta nos projetos analisados. Destacamos um desses fragmentos:

A avaliação será processual e contínua, a partir das observações realizadas durante a aula e através da participação, escrita e aprendizagem dos alunos. Serão observados os seguintes aspectos: participação, interesse, desempenho, engajamento e colaboração. Registraremos os possíveis avanços e dificuldades dos alunos em relação à aprendizagem. (PROJETO X, 2016)

Conforme o fragmento acima, a participação ativa do aluno foi concretizada por meio das avaliações realizadas durante as regências, sendo ela "[...] um instrumento do seu trabalho, articulando-se ao planejamento e à avaliação" (OSTETTO, 2008, p. 13). 


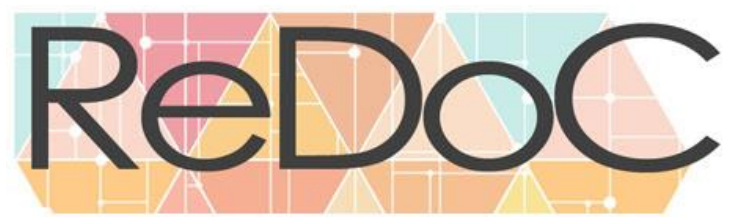

\section{Revista Docência e Cibercultura}

Portanto, foi uma forma de registro das aulas ministradas que possibilitou ampliar o olhar nos possíveis avanços e dificuldades dos alunos.

$\mathrm{Na}$ análise do quinto eixo, buscamos analisar os tipos de materiais utilizados para o desenvolvimento das regências. Os materiais usados foram diversos, sendo materiais recicláveis, eletrônicos, materiais escolares, entre outros, visando aulas diversificadas, produtivas e dinâmicas, baseando sempre nas experiências vivenciadas dentro da sala de aula e considerando a realidade do contexto escolar.

A partir dos dados e da análise, observa-se que os resultados da investigação realizada mostram quais os tipos de metodologias os projetos dos estagiários do Curso de Pedagogia/UFAL utilizaram com mais frequência nas aulas ministradas.

\section{CONSIDERAÇÕES}

Este estudo possibilitou compreender os métodos utilizados pelos estagiários, debatendo questões sobre os princípios de formação de professores, bem como, as metodologias vistas e trabalhadas em sala de aula, conforme registrado em onze projetos de intervenção, realizados a partir da disciplina de Estágio Supervisionado IV.

Cada professor tem sua metodologia de ensino, fundamentada em seus estudos e em sua própria vivência, quando busca desenvolver em espaços educacionais para garantir o processo de aprendizagem. Evidentemente que só o trabalho do professor, isolado de outros profissionais e da família não é o único responsável pela aprendizagem. No entanto, o trabalho docente se constrói e reconstrói com novos conhecimentos e novas experiências.

Considera-se que o desenvolvimento do presente estudo permitiu uma ampliação de um olhar diferenciado, no momento de analisar as metodologias utilizadas nos projetos, como também a análise do uso dos recursos didáticos diferenciados. O uso desses materiais variados e diferenciados tendem a possibilitar o desenvolvimento da 


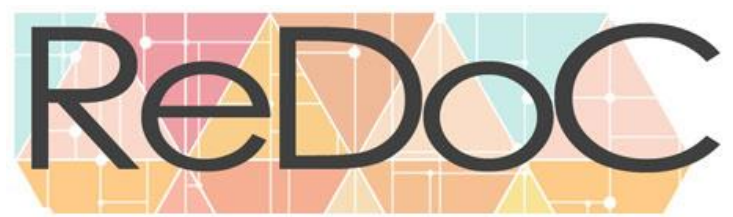

\section{Revista Docência e Cibercultura}

autonomia, da criatividade, como também o desenvolvimento de novos conhecimentos e experiências, contribuindo para um melhor exercício da docência.

Diante dos resultados obtidos na pesquisa, ficou evidente que os futuros profissionais da educação desenvolveram suas práticas pedagógicas buscando diversificar suas propostas metodológicas, mas os recursos didáticos ainda são insuficientes, porém, $20 \%$ dos projetos utilizaram em suas metodologias de ensino jogos, que fornecem uma motivação e enriquecimento, além de divertimento, promovendo uma aprendizagem mais dinâmica; 32\% dos projetos indicaram que foram realizadas atividades expositivas, permitindo que os alunos compreendam o conteúdo de forma atrativa, memorável, apresentando atividades com uma linguagem fácil. Em 31\% dos projetos analisados o aluno participou ativamente das atividades propostas, aproximando-o ao seu cotidiano.

Percebemos que as práticas empregadas nos projetos, os estagiários durante a regência usaram métodos diversificados. Costa et al (2003) evidencia que a prática dos profissionais é diversificada durante a atuação, utilizando como base conhecimentos filosóficos, científicos, sócio-políticos. Os estagiários, no contexto estudado, articularam em suas regências a teoria e a prática.

Entretanto, observa-se que ainda é evidente a repetição de uma prática muito repercute no cotidiano da sala de aula. Desse modo, no contexto da cibercultura, numa sociedade permeada por artefatos digitais que possibilitam novas formas de ensinar e aprender, os profissionais da educação precisam adaptar-se às diversas mudanças evolutivas e progressivas que instigam a escola a dialogar efetivamente com a sociedade.

\section{REFERÊNCIAS}

BEAUCHAMP, Janete; PAGEL, Sandra Denise; NASCIMENTO, Aricélia Ribeiro do (Orgs). Ensino fundamental de nove anos: orientações para a inclusão da criança de seis anos de idade. Brasília: Ministério da Educação, Secretaria da Educação Básica, 2007.

BORSSOI, Berenice. O estágio na formação docente: da teoria a prática, ação-reflexão. UNIOESTE: Cascavel / PR, 2008. 


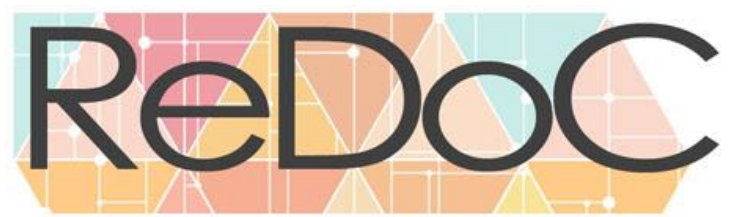

\section{Revista Docência e Cibercultura}

BRASIL. Lei n. 9.394, de 20 de dezembro de 1996. Estabelece as diretrizes e bases da educação nacional. Diário Oficial [da] República Federativa do Brasil. Brasília, DF, 23/12/1996, p.27.833. Disponível em <http://www.planalto.gov.br/ccvil_03/LEIS/19394. htm>. Acesso em 10/2/2017.

CARRER, Andrea Camara. Práticas pedagógicas, profissão docente e formação: perspectivas sociológicas. Perrenoud, Phillippe. Lisboa, Portugal: Dom Quixote, 1993. 205p.

COSTA, C. M; BARros, A. M. A; CAVAlCAnTE, M. A. S. Didática Geral. Maceió: EDUFAL, 2003.

EDUCAÇÃO, Ministério. Apresentação. MEC, 2016. Disponível em: <http://portal.mec.gov.br/institucional/historia>. Acesso em: 01 de maio de 2017.

GERHARDT, T. E; SILVEIRA, D. T. Métodos de pesquisa. Porto Alegre: Editora da UFRGS, 2009, disponível em: <http://www.ufrgs.br/cursopgdr/downloadsSerie/derad005.pdf〉. Acesso em: 08 de abril de 2017.

GIBBS, Graham. Análise de dados qualitativos: Coleção Pesquisa Qualitativa. Bookman Editora, 2009. ISBN $\quad 8536321334,9788536321332$.

GUIMARÃES, A.C. A importância do lúdico nas séries iniciais: o jogo e a brincadeira como elementos didáticos das aulas de educação física. Barra do Bugre-MT. 2014, disponível em: $<$ http://docplayer.com.br/38828708-A-importancia-do-ludico-nas-series-iniciais-o-jogo-e-abrincadeira-como-elementos-didaticos-das-aulas-de-educacao-fisica.html>. Acesso em: $01 \mathrm{de}$ maio de 2017.

GERHARDT, T. E; SILVEIRA, D. T. Métodos de pesquisa. Porto Alegre: Editora da UFRGS, 2009, disponível em: 〈http://www.ufrgs.br/cursopgdr/downloadsSerie/derad005.pdf〉. Acesso em: 08 de abril de 2017.

Conselho Nacional de Educação/Ministério da Educação. Parecer nº 6 de 2005. Reexame do Parecer CNE/CEB 24/2004, que visa o estabelecimento de normas nacionais para a ampliação do Ensino Fundamental para nove anos de duração. Relatores: Murilo de A. Hingel, Maria B. Luci e Artur F. Filho. CEB, Brasília, DF, 08 de junho. 2005.

LEMOS, A. CUNHA, P. (Org.). Olhares sobre a cibercultura. Porto Alegre: Sulina, 2003.

LIBÂNEO, José Carlos. Didática. São Paulo: Cortez, 1994.

MASETTO, Marcos Tarciso, 1937 - Didática: a aula como centro/Marcos Tarciso Masetto. São Paulo. FTD, 1997. - (Coleção aprender e ensinar).

MORAES, Iara Domingos apud Pimenta, Selma Garrido. Um Estudo sobre o Estágio na formação de professores: unidade teoria e práticas? (1994), de Selma Garrido Pimenta. São Paulo: Editora Cortez, 1994. 


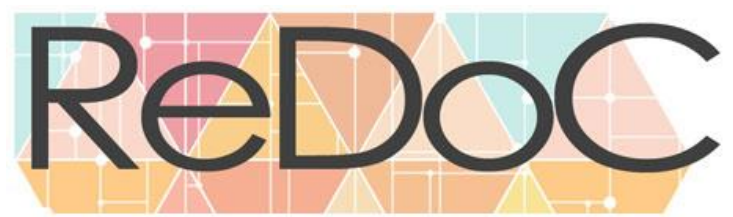

\section{Revista Docência e Cibercultura}

NÓVOA, António, 1954. Formação de professores e trabalho pedagógico. Lisboa: Educa, 2002. ISBN 972-8036-48-5.

NUNES, Célia, 2001 apud Nóvoa, António. Saberes docentes e formação de professores: um breve panorama da pesquisa brasileira. Educação \& Sociedade, disponível em: http://www.scielo.br/pdf/es/v22n74/a03v2274. Acesso em: 15 de março de 2017.

OSTETTO, Luciana Esmeralda. O estágio curricular no processo de tornar-se professor. In: OSTETTO, Luciana E. Educação Infantil: saberes e fazeres da formação de professores. Campinas, SP: Papirus, 2008.

OSTETTO, Luciana E. Observação, registro, documentação: nomear e significar as experiências. In. Educação infantil: saberes e fazeres da formação de professores. Campinas: Papirus, 2008. p. 13-32.

PAÇO, Glaucia Machado. O encanto da literatura infantil no CEMEI Carmem Montes Paixão. Mesquita. Rio de Janeiro, 2009.

FREIRE, Paulo. Pedagogia da autonomia: saberes necessários à prática educativa. São Paulo, Paz e Terra, 2011.

PIMENTA, Selma Garrido; LIMA, Maria. Estágio e docência: diferentes concepções. Revista Poíesis, v.3, n.3 e 4, pp.5-24. 2005/2006.

SANTOS, L. Imaginário tecnológico de professores: ser professor em tempos de tecnologias digitais. Dissertação (Mestrado em Educação) - Pontifícia Universidade Católica do Rio de Janeiro, Rio de Janeiro, 2013.

SAVIANI, Dermeval. Educação escolar, currículo e sociedade: os saberes necessários à formação docente. In: $2^{\circ}$ Simpósio Internacional de Formação Docente: El currículum, um espacio de participación. Campinas, 2009. p.1 - 15.

TARDIF, Maurice. Saberes docentes e formação profissional/Maurice Tardif. Petrópolis, Rio de Janeiro: Vozes, 2012.

VERÇOSA, Elcio. et al. Projeto Pedagógico do Curso de Pedagogia, Alagoas, 2006.

VICENTINI, Paula Perin; LUGLI, Rosário Genta. História da profissão docente no Brasil: representações em disputa. São Paulo: Cortez, v. 4. p.27 - 66, 2009. 